\title{
SCIENTIFIC OPHTHALMOLOGY
}

For a number of years the Editorial Committee of this Journal has received criticism from its readers that too much of its space has been devoted to the scientific and more academic aspects of ophthalmology and too little to purely clinical subjects. It is undoubtedly sad that so many of those who practise our specialty are content to keep themselves abreast of its practical applications without much care for the fundamental principles on which these applications are built. Nevertheless, it is certainly true that as he gets older and set in his mental habits the clinician is apt to lose touch with the scientist, and as the latter becomes more involved in the mysteries of the techniques of his laboratory and tends more and more to ascend into his own particular golden clouds, the former increasingly fails to appreciate his thoughts or even to understand his meaning.

For these reasons the Editorial Committee extends a warm welcome to the appearance or imminent appearance of three journals which are to be devoted purely to the scientific aspects of ophthalmology:

Vision Research, an international journal published bi-monthly by the Pergamon Press Ltd., with the following Board of Editors: T. Shipley (Miami) (Chairman), F. Crescitelli (Los Angeles), H. J. A. Dartnall (London), Y. Le Grand (Paris), H. Schober (Munich), and A. Sorsby (London). The first issue appeared in June, 1961.

Experimental Eye Research, published quarterly by the Academic Press, the Editors-in-Chief being H. Davson (London) and E. A. Balazs (Boston), and the Editorial Board comprising J. H. Kinoshita (Boston), V. E. Kinsey (Detroit), D. Maurice (London), Louise L. Sloan (Baltimore), and G. K. Smelser (New York). With them is associated an international Advisory Board. The first issue is promised by the Autumn, 1961.

Investigative Ophthalmology, to be published by the Mosby Co. of St. Louis, which is scheduled to appear bi-monthly from January, 1962. This journal is sponsored by the Association for Research in Ophthalmology of the U.S.A. The Editor is B. Becker (St. Louis), and the Editorial Board, drawn from the Association, is as follows: J. Allen, E. Ballintine, J. Harris, M. Hogan, J. Kinoshita, V. E. Kinsey, I. Leopold, K. Ogle, A. Potts, G. Smelser, K. Swan, and L. Zimmerman.

Up to the present time those engaged in research on the eye and vision have had difficulty in finding space for publication in any journal except the ophthalmological journals which are essentially clinical. Now it would appear that a plethora of space is to be available and, indeed, if three journals are to survive in this relatively narrow subject, the scientists associated with the specialty will have to work even harder than before. At the same time, it allows a journal such as ours to concentrate much more on clinical material. It may be arguable if this is entirely a good thing, unless the clinicians subscribe to the new feast that is being prepared for them. Whether or not this Journal maintains its standard, of course, does not lie primarily with the Editorial Committee since they have perforce to publish papers submitted to them although they naturally reserve the right of eclectic choice - and have, indeed, over recent years, always with regret and apologies, returned some twenty-five per cent. of such papers. It is up to the ophthalmologists to make good the deficiency in scientific material by submitting a greater number of still more excellent contributions of a clinical nature. 